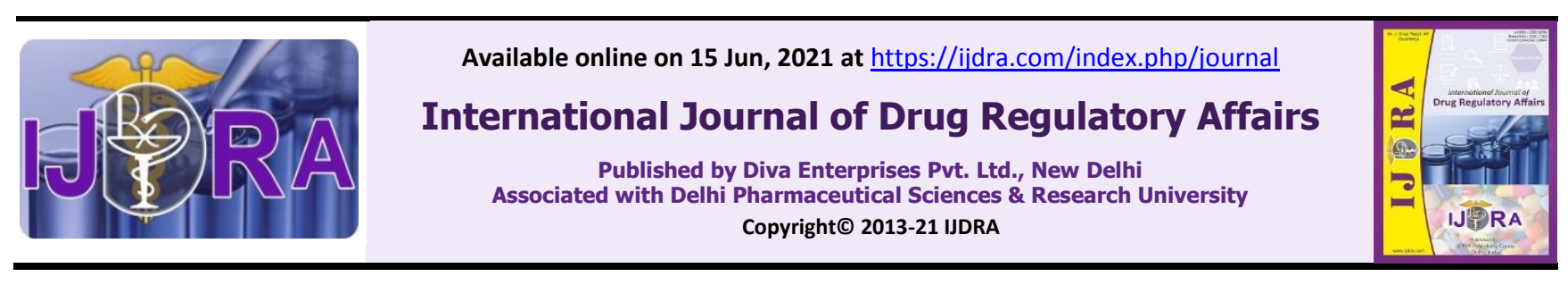

Review Article

Open Access

\title{
Regulatory aspects for competitive Generic Therapies in USA
}

\author{
Himani Patel*, Iva Dhulia, Umesh Dobariya, Nidhi Pardeshi, Yogesh Katariya \\ Department of Regulatory Affairs, Isazi Pharma and Techno Consultancy Private Limited, Vadodara, Gujarat, India - 390007
}

\section{Abstract}

The FDA Reauthorization Act (FDARA) of 2017 lets generic companies ask for expedited review and 180-day exclusivity for a Competitive Generic Therapies (CGT)-designated product. (1)

FDA guidance for industry on Competitive Generic Therapies (CGT) provides keen information for generic drug manufacturers who want to develop a drug with inadequate generic competition. This guideline is specially published for generic players. If you are a generic manufacturer or sponsor, this will

- Explain the process and criteria to request and designate a drug as a CGT.

- Information on the actions FDA may take to expedite the development and review of ANDAs designated as CGT.

- Implementation of 180-day exclusivity period for certain first approved applicants that submit ANDAs for CGTs. (1)

Keywords: FDA Reauthorization Act (FDARA), FD\&C Act, ANDA, Competitive Generic Therapy, Inadequate Generic Competition

Article Info: Received 19 Apr. 2021; Review Completed 01 Jun. 2021; Accepted 05 Jun. 2021

Cite this article as:

Patel H, Dhulia I, Dobariya U, Pardeshi N, Katariya Y. Regulatory aspects for competitive Generic Therapies in USA. Int J Drug Reg Affairs [Internet]. 2021 Jun 15 [cited 2021 Jun 15]; 9(2):16-19. Available from:

http://ijdra.com/index.php/journal/article/view/463

DOI: 10.22270/iidra.v9i2.463

*Corresponding author

\section{Introduction}

FDA recognizes that various factors may influence an applicant's decision to develop a certain generic drug. For instance, some drugs may not attract a high level of interest from generic drug applicants if there is a limited market for those products and/or if the products are more difficult to develop. Nevertheless, these drugs can play an important role in diagnosing, treating, and preventing various types of diseases or conditions, and incentivizing generic competition for these products can help ensure that patients have access to the medicines they need. Therefore, to incentivize the development and timely entry of generic drugs where there is inadequate competition, FDA has created a new approval pathway called Competitive Generic Therapy (CGT). Under this new pathway, FDA may designate a drug with "inadequate generic competition" as a Competitive Generic Therapy (CGT) and help applicant to expedite the development and review of the ANDA. (2) The term "inadequate generic competition" means, with respect to a drug, there is not more than one approved drug listed in the active section of the orange book. (3)

The FDA Reauthorization Act (FDARA) was signed into law on August 18, 2017. As part of FDARA, Generic Drug User Fee Amendments were reauthorized and
Federal Food, Drug, and Cosmetic Act (FD\&C Act) was amended to add section $506 \mathrm{H}$ for Competitive Generic Therapy (CGT). (2, 4)

\section{Key benefits of Competitive Generic Therapy (CGT) are}

Expedited Development: To facilitate expedited development, applicants may request a pre-ANDA meeting (i.e., either a product development meeting or a pre-submission meeting) for drugs designated as CGT.

Expedited Review: To facilitate expedited review, FDA strives to act on the ANDA as soon as possible, including prior to the GDUFA goal date.

Eligibility for 180-day market Exclusivity: FDARA has created a new type of 180-day market exclusivity for the first approved applicant of a drug with a CGT designation for which there were no unexpired patents or exclusivities listed at the time of original submission of the ANDA. $(2,4)$

\section{Competitive Generic Therapy Designation}

Process, Criteria and Timing for submitting a request for CGT designation 
FDA may designate a drug as a CGT after determining that there is inadequate generic competition for that drug. As described earlier, the term "inadequate generic competition" means, with respect to a drug, there is not more than one approved drug listed in the active section of the orange book. Accordingly, each applicant that wishes to request designation of a drug as a competitive generic therapy should submit a request to FDA for such designation and are known as Requests for Designation. If an applicant believes that the information listed in the Orange Book is incorrect (i.e., if an applicant has information indicating that a drug listed in the active section of the Orange Book has been withdrawn from sale), the applicant should submit a controlled correspondence prior to submitting a Request for Designation seeking correction of the relevant information in the Orange Book. $(2,5)$ The Request for Designation should be submitted only after FDA removes the drug from the active section of the Orange Book. $(2,4)$

Applicants may submit requests to designate a drug as a CGT (Requests for Designation) concurrently with, or at any time prior to, the original ANDA submission. FDA will not consider Requests for Designation as timely if they are submitted after the submission of the original ANDA, including as an amendment during filing review. Exception to this, a Request for Designation may be considered timely if, after the applicant receives an RTR (Refuse to Receive) letter, the request is included as part of, or is submitted any time prior to, the resubmission of the amended ANDA that FDA determines to be substantially complete. However, FDA may deny a Request for Designation if at the time the request is submitted a Request for Reconsideration and/or Request for Formal Dispute Resolution related to an RTR decision remains pending with the Agency. (2)

FDA will assess the Request of Designation within 60 calendar days of receipt of the applicant's request and will send the determination to the applicant via FDA correspondence. FDA, in assessing whether inadequate generic competition for a particular drug exists, will rely on the information contained in the Orange Book at the time it makes its determination. $(2,4)$

\section{Process for Submitting a Request for Designation}

\section{Request for Designation can be made in two ways -}

\section{A). Prior to Submission of an ANDA}

\section{B). Submitted with an Original ANDA}

As discussed earlier, Requests for Designation may be made at any time prior to the submission of an original ANDA or concurrently with the submission of an original ANDA. The applicant should obtain, from FDA, a pre-assigned ANDA number prior to submitting a Request for Designation. Request for Designation can be submitted as a stand-alone or as an accompaniment to the pre-submission facility correspondence (PFC) for an ANDA. (6) If an applicant plans to request a pre-ANDA meeting for a drug for which it also wishes to seek designation as a CGT, the applicant should submit a Request for Designation before submitting a meeting request. (2)

\section{Content of Requests for Designation}

Applicants should include the following information in their cover letter for a Request for Designation:

- Pre-assigned ANDA number

- A statement supporting the Request for Designation under section $506 \mathrm{H}$ of the FD\&C Act. This statement should include sufficient identification of the particular drug product/reference listed drug that will serve as the basis of submission for the applicant's proposed application (i.e., the application number, the proprietary name (if applicable), and the strength(s) for the drug for which CGT designation is being sought).

- Information supporting the applicant's assertion that there is "inadequate generic competition" as defined in section $506 \mathrm{H}(\mathrm{e})(2)$ of the FD\&C Act.

If applicants submit a Request for Designation concurrently with submission of an original ANDA, they should prominently identify the request in the cover letter to the submission in Module 1 of the Common Technical Document. (2)

\section{Considerations for Expedited Development and Review of Competitive Generic Therapies}

\section{Considerations for Expedited Development}

Applicants for drugs that FDA has designated as CGTs may request expedited development and review of their ANDAs. Applicants may request a pre-ANDA meeting (i.e., either a product development meeting or a pre-submission meeting) for a CGT. FDA will consider requests for meetings that may expedite the development of a drug designated as a CGT on a case-by-case basis. for both complex and non-complex products, provided a meeting is determined to be appropriate considering factors like the complexity of developing an application for the specific drug, potential public health impact of the product, including the severity of the condition treated and the size of the impacted patient population, as well as the availability of therapeutic alternatives and last but not least the impact on FDA resources and other existing workload commitments. $(2,4)$

For example, if development of an ANDA may raise specific scientific questions, such as when (a) FDA has not issued a product-specific guidance (PSG) for the drug and published general guidance on bioequivalence is not applicable or (b) the applicant has proposed an alternative equivalence evaluation (i.e., a change in study type, such as from an in vitro study to a comparative clinical endpoint study) for a product for which FDA has issued a PSG, FDA may grant an applicant's request to meet with FDA to discuss these questions. $(2,4)$

Similarly, if the applicant wants to discuss and explain the format and content of the ANDA to be submitted (e.g., the types of data that will be contained in the ANDA, the data that will support equivalence claims), an applicant may submit a request for a pre-submission meeting for a drug designated as a CGT. $(2,4)$ 


\section{Considerations for Expedited Review}

As part of expediting the review of a drug that has been designated as a CGT, FDA will strive to act on the ANDA as soon as possible, including prior to the GDUFA goal date, if possible.

FDA may offer a mid-review-cycle meeting to an applicant of an ANDA for a drug designated as a CGT during the first review cycle. The mid-review-cycle meeting will generally take place within 30 days after the mid-point of the review cycle. The mid-review-cycle meeting affords an opportunity for FDA to discuss issues identified during review with the applicant to expedite the review and approval process further.

FDA may involve experienced review and regulatory health project management staff in a collaborative, cross-disciplinary review of an ANDA for a drug designated as a CGT. Senior management or crossdisciplinary project lead can also be involved to expedite the review process.

FDA is committed to improving the predictability and transparency of all ANDA assessments, including assessments of ANDAs for drugs designated as CGTs, to help minimize the number of review cycles necessary for approval. $(2,4)$

\section{Competitive Generic Therapy Exclusivity}

FDARA created a new type of 180-day marketing exclusivity period for ANDA applicants of certain drugs that FDA has designated as CGTs. This exclusivity is commonly referred to as "CGT exclusivity" and will be applicable first approved applicant that

- Obtains approval of an ANDA for a drug that has been designated as a CGT and for which there were no unexpired patents or exclusivities listed in the Orange Book for the relevant RLD at the time the applicant submitted the original ANDA to the Agency.

- Commercially markets such drug within 75 calendar days after the approval of the ANDA.

To ensure that FDA receives timely notification of first commercial marketing, the first approved applicant should submit correspondence to the ANDA informing the agency that it has commenced marketing. The FDA recommends that the first approved CGT applicant send a general correspondence to the FDA informing them that they have commenced commercial marketing, and that a duplicate be submitted to the FDA Office of Generic Drugs' patent and exclusivity team, at CDEROGDPET@fda.hhs.gov

There can be multiple first approval applicants for the same CGT, if all such ANDA applicants obtain approval for the same CGT on the same day, and such approvals constitute the first ANDA approvals for this CGT.

An ANDA applicant may still qualify as a first approved applicant even if another ANDA referencing the same RLD, but without a CGT designation, is approved prior to the approval of the first approved applicant's ANDA.
FDA does not consider the prior ANDA approval to constitute the first approval of an ANDA for a CGT.

The 180-day CGT exclusivity period is triggered by the first commercial marketing of the competitive generic therapy (including the marketing of an authorized generic) by any first approved applicant. FDA is not restricted from approving other ANDAs that are the same as the CGT prior to or after the approval of a first approved applicant's ANDA for the CGT unless and until the first approved applicant has commenced commercial marketing. (7)

CGT exclusivity will be forfeited if the applicant does not market the CGT within 75 days after the date on which the corresponding ANDA is made effective.

FDA intends to permit a first approved applicant to relinquish and/or grant selective waiver of CGT exclusivity, similar to the aforementioned 180-day firstto-file patent challenge exclusivity. (2-4)

FDA's Office of Generic Drugs publishes a list on the FDA website of all approved ANDAs for drug products that received CGT designation, and indicates which ANDAs were also eligible for CGT exclusivity. The list is updated every two weeks. The Orange Book also posts a CGT code in the "Exclusivity Data" section. (7)

\section{Key points to be considered for planning CGT}

Though CGT offers 180-day Exclusivity, this unlike Paragraph IV "first filer" exclusivity, CGT exclusivity is obtained upon the "commercial marketing" of the approved CGT product, not FDA approval. Additionally, a manufacturer sacrifices its entitlement to the 180-day exclusivity should they fail to commercially market the drug within 75 days of receiving FDA approval. $(8,9)$

CGT exclusivity could also present potential pitfalls to applicants, as there is a possibility other competitor may receive ANDA approval even after approval of the first approved CGT. Should they receive FDA approval prior to the first approved CGT's commercial launch? (9)

Still, with careful planning and coordination, CGT presents a useful and potentially lucrative pathway for generic drug manufacturers. Considering few points listed below, generic manufacturers can take maximum advantage of CGT pathway. (9)

\section{1). Request for Designation Early}

Though FDARA allows CGT designation at any time up to and including ANDA submission, an early determination will better allow CGT applicants to develop the coordinated regulatory and commercial strategy necessary to reap the full benefits of potential CGT exclusivity. (9)

\section{2). Request for Expedited Development and Review}

FDA guidance provides considerations for expedited development and review, and actions FDA may take to expedite development and review, but FDA is not required to take any action. This is rooted in the statutory language of Section $506 \mathrm{H}$ of the FDC Act, which provides that the Secretary may, at the request of an 
applicant, expedite the development and review of an ANDA for a drug designated as a CGT. (7)

\section{3). Plan to Commercially Market Immediately}

Given that rapid commercial marketing is necessary to ensure the full benefit of CGT exclusivity, internal departments should closely coordinate along with any third parties in the supply chain to ensure that the company's commercial marketing effort is ready to proceed immediately upon approval. (9)

\section{4). Notify the FDA at Start of Commercial Marketing}

Generic manufacturers should notify the FDA when it commences commercial marketing of a CGT drug product, in order to ensure that they are entitled to the full scope of their CGT exclusivity. (9)

\section{5). Consider CGT Despite Potential Competition}

Finally, generic manufacturers should also consider seeking a CGT designation despite the presence of potential competition. For example, Company A. received the first approval for a CGT product, $\mathrm{X}$, despite the fact that a generic competitor had already received approval to market product X. Only Company A's product was designated as a CGT, likely because the other generic competitor did not apply for a CGT designation. Thus, generics should consider seeking a CGT designation so long as there is "inadequate generic competition, "even if another generic manufacturer is already seeking approval for such a drug. (9)

\section{Conclusion}

Applicants that are developing generic drugs which meet the criteria for CGT designation should consider submitting a request to FDA and take benefit of expedited development and review as well as 180-day exclusivity whenever possible. Applicants should plan immediate commercialization to avail full 180-day exclusivity as this exclusivity starts from the commercializing and not from the approval, it doesn't delay approval of other generics. (10-14)

\section{Acknowledgements}

The authors are very much thankful to Isazi Pharma and Techno Consultancy for their support and constant encouragement.

Financial Disclosure statement: The authors received no specific funding for this work.

\section{Conflict of Interest}

The authors declare that there is no conflict of interest regarding the publication of this article.

\section{References}

1. Competitive Generic Therapies [Internet]. USFDA; 2020 [cited 2021 Apr 07]. Available from: https://www.fda.gov/regulatory-information/search-fdaguidance-documents/competitive-generic-therapies

2. Competitive Generic Therapies, Guidance for Industry [Internet]. USFDA; 2020 [cited 2021 Apr 01]. Available from:

https://www.fda.gov/media/136063/download
3. Federal Food, Drug, And Cosmetic Act, Section 506H(e)(2)(A) [Internet]. Federal Food, Drug, And Cosmetic Act; [updated 2021 Jan 05; cited 2021 Apr 02]. Available from: https://www.govinfo.gov/content/pkg/COMPS973/pdf/COMPS-973.pdf

4. Federal Food and Drug Reauthorization Act, Section 803 [Internet]. Federal Food and Drug Reauthorization Act; 2017 Aug 18 [cited 2021 Apr 01]. Available from: https://www.congress.gov/115/plaws/publ52/PLAW115publ52.pdf

5. Controlled Correspondence Related to Generic Drug Development Guidance for Industry, Guidance for Industry [Internet]. USFDA; 2020 [cited 2021 Apr 07]. Available from: https://www.fda.gov/media/109232/download

6. ANDAs: Pre-Submission of Facility Information Related to Prioritized Generic Drug Applications (Pre-Submission Facility Correspondence), Guidance for Industry [Internet]. USFDA; 2017 [cited 2021 Apr 03]. Available from:

https://www.fda.gov/media/105794/download

7. Federal Food and Drug Reauthorization Act, Section 803 [Internet]. Federal Food and Drug Reauthorization Act. 2017 Aug 18 [cited 2021 Apr 02]. Available from: https://www.congress.gov/115/plaws/publ52/PLAW115publ52.pdf

8. Alan Minsk, Seth Ray, Competitive Generic Therapies: FDA Issues Final Guidance [Internet]. Jdsupra; 2020 Jun 03 [cited 2021 Apr 01]. Available from: https://www.jdsupra.com/legalnews/competitive-generictherapies-fda-28268/

9. Thomas Sullivan, FDA Publishes Final Guidance on Competitive Generic Therapies, Policy and Medicine, Rockpointe Publications [Internet] policymed; 2020 [updated 2020 May 06, cited 2021 April 06]. Available from: https://www.policymed.com/2020/05/fda-publishes-finalguidance-on-competitive-generic-therapies.html

10. Sailesh K. Patel, Thomas A. Rammer II, Competitive Generic Therapy Exclusivity Offers Benefits, Schiff Hardin [Internet]. Schiffhardin; 2019 Apr 25 [cited 2021 Apr 06]. Available from:

https://www.schiffhardin.com/insights/publications/2019/co mpetitive-generic-therapy-exclusivity-offers-benefits

11. Prasad V, Kale P. Complex Generics: Opportunities \& Challenges. Int J Drug Reg Affairs [Internet]. 2018 Feb 13 [cited 2021 Jun 15];4(3):1-10. Available from: http://ijdra.com/index.php/journal/article/view/184

12. M SK, Katamreddy JD, P JR. A review on ANDA submission requirements for Generic drugs: "Paragraph IV certification" as per FDA CDER guidelines. Int J Drug Reg Affairs [Internet]. 2018 Sep 15 [cited 2021 Jun 15];6(3):512. Available from: http://ijdra.com/index.php/journal/article/view/260

13. Shah S, Badjatya JK. Preliminary requirement for filing application in US. Int J Drug Reg Affairs [Internet]. 2018 Dec 20 [cited 2021 Jun 15];6(4):1-. Available from: http://ijdra.com/index.php/journal/article/view/276

14. Kashyap P, Duggal E, Budhwar P, Badjatya JK. MARKETING AUTHORIZATION OF GENERIC DRUG: GLOBAL ISSUE AND CHALLENGES. Int J Drug Reg Affairs [Internet]. 2013 Oct 31 [cited 2021 Jun 15];1(3):1-6. Available from: http://ijdra.com/index.php/journal/article/view/5 